\title{
A AFINIDADE COM A FÍSICA: UMA ANÁLISE FEITA COM ESTUDANTES DA UNIVERSIDADE FEDERAL DO MATO GROSSO DO SUL (UFMS)
}

\author{
Bruno dos Santos Simões* \\ Ana Luiza de Quadros** \\ Simoni Tormöhlen Gehlen*** \\ Hamilton Perez Soares Corrêa**** \\ Rodolfo Langhi*****
}

RESUMO: Este trabalho tem como objetivo investigar fatores que influenciaram estudantes de Física da Universidade Federal do Mato Grosso do Sul (UFMS) na escolha do curso, e o papel que seus próprios professores tiveram nessa escolha. Para tal, construímos e aplicamos um questionário a quarenta e cinco graduandos de Física (bacharelado e licenciatura). Dentre os resultados, destacamos que os estudantes investigados desenvolveram afinidades com a Física antes de optarem pela carreira. Ao apontarem professores dos quais tenham gostado durante o percurso de formação, aqueles que ministraram Física foram os mais lembrados. Porém, a afinidade com o conhecimento é o fator mais citado como definidor da escolha. Entendemos que o professor, mesmo não sendo peça fundamental nessa escolha, é um importante agente motivador, influenciando estudantes na escolha pela carreira científica.

Palavras-chave: Afetividade. Ensino de Física. Escolha da Carreira.

\section{THE AFFINITY WITH PHYSICS KNOWLEDGE: AN ANALYSIS FROM THE GRADUATE STUDENTS OF PHISICS UFMS}

ABSTRACT: The aim of this study is to investigate aspects that influenced students of Physics at the Federal University of Mato Grosso do Sul (UFMS) to choose that course and the influence that their own teachers had on their decision. In order to do that, a questionnaire was prepared and answered by forty-five students of Physics (bachelor's course or teacher's course). In the results we highlighted that those students developed affinities with physics knowledge before choosing the course. The analysis suggests that the teacher, although not predominant in these choices, is an important catalyst, thus influencing students to choose a career in science co-operating.

Keywords: Affectivity. Physics education. Career choice.
* Licenciado em Física pela Universidade Federal de Mato Grosso do Sul (UFMS) e Mestre em Educação Científica e Tecnológica pela Universidade Federal de Santa Catarina (UFSC). Email: simoes89@uol.com.br

* *Doutora em Educação pela Faculdade de Educação da Universidade Federal de Minas Gerais (FAE/UFMG). Professora Assistente do Departamento de Química no Instituto de Ciências Exatas da (IQUFMG). Email: aquadros@qui.ufmg.br

* * Doutora em Educação Ciêntífica e Tecnológica pela Universidade Federal de Santa Catarina (UFSC). Professora adjunta do Departamento de Ciências Exatas e

Tecnológicas da Universidade Estadual de Santa Cruz (UESC). Email: simonigehlen@yahoo.com.br

* * * Doutor em Química pela Universidade Estadual Paulista (UNESP). Professor Adjunto do Centro de Ciências Exatas e Tecnológicas da Universidade Federal de Mato Grosso do Sul (UFMS). Email: hpsoares@gmail.com

***** Doutor em Educação Para a Ciência pela Universidade Estadual Paulista Júlio de Mesquita Filho (UNESP/Bauru). Professor Assistente Doutor do Departamento de Física da Faculdade de Ciências da UNESP/Bauru.

Email: prof.langhi@gmail.com 


\section{INTRODUÇÃO}

A relação dos conteúdos científicos com o contexto social dos estudantes tem sido amplamente discutida com o objetivo de promover aprendizagens que os auxiliem a entender melhor o mundo em que vivem, a fim de que atuem nele de forma consciente. Porém, outras estratégias que podem proporcionar mais qualidade ao ensino têm recebido atenção. Entre elas, podemos destacar as aulas dialogadas (MORTIMER \& SCOTT', 2003), o ensino a partir das concepções prévias (MORTIMER, 1996; SCHNETZLER, 1992) e a implementação de um ambiente afetivo. Sabe-se que os conhecimentos escolares devem estar comprometidos com o sentido coletivo da vida e do trabalho e, para isso, devem considerar a criticidade, a responsabilidade ambiental e social, a motivação dos estudantes, entre outros fatores.

No ensino de Ciências, vários estudos (VILLANI \& CABRAL, 1997; PIETROCOLA \& PINHEIRO, 2000; CUSTÓDIO, 2007; QUADROS et al., 2005; DALRI \& MAT'TOS, 2008) foram desenvolvidos nas últimas décadas, destacando aspectos ligados a questões de afetividade e de motivação do sujeito como fatores importantes no processo de ensino e aprendizagem.

Destacamos o trabalho de Quadros et al. (2005), em que os autores apresentam uma investigação feita junto aos estudantes do curso de Licenciatura em Química da Universidade Federal de Minas Gerais (UFMG). Nele, são analisados fatores que influenciam na formação da identidade docente e na opção pela carreira desses estudantes. Para os autores, vários fatores estão envolvidos nessa escolha, entre eles as características mais marcantes de um professor, que estão ligadas a fatores pedagógicos e afetivos, tais como a metodologia usada, a amizade, o companheirismo, o bom humor, o diálogo constante e a atenção.

De forma análoga investigamos, neste trabalho, os fatores que influenciaram os estudantes de Física da Universidade Federal do Mato Grosso do Sul (UFMS) na escolha do curso, e a participação que seus professores tiveram nessa escolha.

Para isso, levantamos as seguintes questões: De que maneira o professor de Ciências pode ter exercido influência nos alunos que ingressaram no curso de Física da UFMS? Que aspectos principais permeiam a relação entre professor e estudante e que são consideradas importantes pelos graduandos em Física? Que outros fatores, além do professor, contribuem para que os estudantes de Ensino Médio optem pela carreira de físico?

Para argumentarmos em torno desses questionamentos, usamos as categorias construídas por Quadros et al. (2005) e nos baseamos em outros autores que já desenvolveram estudos nessa área, brevemente apresentados a seguir.

\section{AFETIVIDADE NO ENSINO DE CIÊNCIAS}

Há estudos e pesquisas em Educação que buscam discutir aspectos ligados a questões da afetividade e à motivação do sujeito como fatores fundamentais 
no processo de ensino e aprendizagem (MACHIORE \& ALENCAR, 2009; SILVA \& SCHNEIDER, 2007), inclusive no ensino de Ciências (VILLANI \& CABRAL, 1997; PIETROCOLA \& PINHEIRO, 2000; QUADROS, et al., 2005; CUSTÓDIO, 2007; DALRI \& MATTOS, 2008; MARTINI, 2006).

Dalri e Mattos (2008) afirmam que as escolhas que fazemos durante nossa vida são direcionadas por experiências vividas e pela forma como aprendemos a representar as coisas do mundo. Nesse contexto, a escolha pela profissão de físico ou professor de Física é norteada pelas relações que esse sujeito constrói com o saber físico e pedagógico. Porém, valores como status, poder, recompensas salariais, também podem estar presentes.

Martini (2006) defende que os indivíduos se apropriam dos elementos culturais construídos pelo homem ao longo da história por meio das interações sociais. Nessas interações, o professor atua como mediador, assumindo um papel importante na construção do conhecimento dos estudantes, e estes incorporam também os modos de pensar, agir e sentir, enquanto se constituem sujeitos. As decisões sobre o tipo de prática de ensino adotado pelo professor têm inúmeras implicações afetivas no comportamento dos estudantes, influenciando sua relação com os objetos de conhecimento escolares, determinando, em última análise, a natureza dos vínculos que estabelecem com esses objetos.

Quadros et al. (2005), que focaram seu trabalho na formação de professores, afirmam que:

A peculiaridade da formação do professor, por ter em seu mundo de trabalho o mesmo "espaço" no qual foi formado, ou seja, a sala de aula favorece a que ele assuma, depois de formado, não só a posição física de seus professores, mas também a postura, atitudes, formas de ensinar e etc., fazendo um efeito "espelho". (p. 7)

Para esses autores, cada um de nós carrega uma imagem ou modelo de professor que é formada durante todo o período de escolarização e que, com o acréscimo de outros saberes obtidos na licenciatura ou incorporados pela própria prática, constroem a nossa identidade como profissionais e como professores, interferindo diretamente nas ações e opções que fazemos.

Para Von Hohendorff (1999), que realizou releituras de Freud sobre psicologia escolar, o papel do professor na relação com o estudante vai além de transmitir conhecimento. É importante que o próprio professor entenda que o lugar que ocupa em relação a seus alunos não é apenas o de ensinar, mas o de formar sujeitos (VON HOHENDORFF, 1999).

Do ponto de vista da prática pedagógica, compreende-se que fortalecer a afetividade na relação entre professores e estudantes favorece a autoestima, o diálogo e a socialização, colocando em evidência esse caráter unificador promovido pelas emoções (SILVA \& SCHNEIDER, 2007). Esses autores ressaltam, ainda, que a afetividade é importante no processo de avaliação, afastando o risco de eventuais antipatias entre professor e estudantes. 
Villani e Cabral (1997) utilizam pressupostos da psicanálise em seus trabalhos, levando em consideração aspectos afetivos e motivacionais que permeiam o sujeito estudante. Os autores mencionam que para engajar o estudante nas aulas, é necessário que o professor considere suas ideias, saiba lidar com elas, incentive a discussão e auxilie em sua evolução. Nesse contexto, não há espaço para censura de ideias. Isso denota claramente um aspecto afetivo nas relações de sala de aula.

Os resultados de outro estudo nessa linha foram publicados por Custódio (2007). Ao discutir aspectos da afetividade no processo de ensino e aprendizagem, o autor visa compreender a dimensão afetiva das explicações que os estudantes constroem sobre o mundo e entender a incorporação e operacionalização de conhecimentos científicos, a fim de contemplar padrões afetivos envolvidos. Embora as explicações sejam o elemento essencial na comunicação dos saberes na sala de aula, não são muito claros os mecanismos que levam alguém a aceitar e/ou entender uma explicação (CUSTÓDIO, 2007). Nesse contexto, o autor conclui que os vínculos afetivos criados com o conteúdo físico e com o professor de Física são fatores cruciais no processo de ensino e aprendizagem. Para ele, os estudantes conseguem entender melhor as explicações de seus professores se houver várias ligações afetivas dentro do ambiente da sala de aula.

Para Pietrocola e Pinheiro (2000), o professor consegue desenvolver melhor o seu trabalho de sala de aula quando utiliza práticas pedagógicas que integram os estudantes no processo de aprendizagem. E esse aluno aprende melhor quando consegue ver no professor alguém que compartilha e entende suas dificuldades, anseios e necessidades. São os vínculos afetivos que tornam a aprendizagem mais eficiente e concreta (PIETROCOLA \& PINHEIRO, 2000).

De acordo com Silva e Schneider (2007), apesar de valorizarmos a afetividade como elemento importante na relação entre professor e estudantes, é importante ressaltar que isso não é garantia de aprendizado. São igualmente importantes as estratégias didáticas, a qualidade das intervenções do professor e também o modo como planeja e utiliza os recursos em sala de aula. Além disso, os autores consideram importante a diversificação de estratégias, por meio de metodologia de projetos, de aulas-passeio, da dramatização, do uso do lúdico, entre outros (SILVA \& SCHNEIDER, 2007).

Para encontrarmos algumas evidências que nos permitam argumentar melhor sobre a influência do professor na opção pela carreira de físico entre os estudantes de graduação em Física da UFMS, desenvolvemos este estudo.

\section{METODOLOGIA}

Neste trabalho, investigamos os elementos que influenciaram ou influenciam os jovens e adolescentes na escolha pelo curso de graduação em Física, licenciatura e bacharelado, da UFMS. Para tal, definimos o percurso da investigação e caracterizamos o nosso campo de investigação. 


\section{a) 0 percurso da investigação}

Este trabalho faz uma análise qualitativa envolvendo os aspectos que interferem na escolha pelo curso de graduação em Física, dos estudantes de bacharelado e licenciatura da UFMS. Para tal análise, fazemos uso de dados quantitativos, coletados no ambiente em que os investigados estudam. Para Garnica (1997), na análise qualitativa, o termo pesquisa passa a ser concebido como uma trajetória circular em torno do que se deseja compreender, voltando o olhar para a qualidade e para os elementos que são significativos para o pesquisador. Os métodos qualitativos são voltados especificamente para os chamados "fenômenos humanos", com o intuito de elucidar e conhecer os complexos processos de constituição da subjetividade.

Baseados em André (2009), argumentamos que este trabalho usa técnicas tradicionalmente associadas à etnografia, tais como a coleta de dados em seu ambiente natural e a análise dos dados considerando o contexto cultural no qual os sujeitos estão inseridos.

Optamos pelo uso do questionário como instrumento de coleta de dados, considerando-o como um conjunto de questões pré-elaboradas, sistemáticas e sequencialmente dispostas em itens que constituem o tema de nossa investigação. O questionário foi construído com vinte perguntas, tendo dez delas o objetivo de caracterizar os pesquisados e sendo as outras dez relativas aos objetivos do trabalho. As questões de caracterização dos investigados eram simples, solicitando dados sobre o tipo de escola que cursou durante a educação básica (Fundamental e Médio); a época em que concluiu o Ensino Médio; o ano em que ingressou no Ensino Superior; a modalidade que cursa atualmente (bacharelado ou licenciatura) e se a modalidade atual coincide com a modalidade de ingresso; além de dados gerais envolvendo sexo, idade, semestre do curso. Oito das questões relativas ao objetivo do trabalho eram abertas, e duas de múltipla escolha.

As questões abertas envolviam perguntas em que o sujeito pôde expor sua opinião livremente frente ao assunto inquirido, e as questões fechadas foram formadas por perguntas em que o sujeito escolheu, dentre uma gama de opções, aquela que mais se aproximava de sua opinião sobre o assunto inquirido (GIL, 2006).

O questionário foi aplicado em todas as turmas da Física da UFMS, tanto do curso de licenciatura como do bacharelado, com estudantes matriculados no $1^{\circ}$ semestre de 2010 e regularmente frequentes nos cursos. O curso de Física da UFMS tem ingresso anual com 25 vagas para cada um dos cursos, licenciatura e bacharelado. Entretanto, possui um número reduzido de alunos em cada uma das turmas, principalmente nos semestres finais do curso. Alguns alunos em final de curso frequentam poucas disciplinas, o que dificultou a entrega dos questionários. Do total de estudantes, 65 receberam o questionário e 45 retornaram respondidos. Para a análise dos questionários, usamos as mesmas categorias do trabalho de Quadros et al. (2005) para analisar as memórias dos entrevistados sobre o professor que descreviam. Essas categorias levaram em consideração as referências afetivas, pedagógicas e de conhecimento. 


\section{b) Caracterizando o campo de pesquisa}

Os cursos de Física da UFMS, licenciatura e bacharelado, iniciaram suas atividades, respectivamente, em 1981 e 1991. Inicialmente, o curso de licenciatura era noturno, na modalidade de licenciatura curta, com habilitação em Física. Em 1983, passou a ser diurno, na modalidade de licenciatura plena. A grade curricular é de quatro anos ou oito semestres, e se desenvolve nas dependências do Centro de Ciências Exatas e Tecnologia da UFMS, localizado na cidade de Campo Grande/MS.

Até 2009 tanto o bacharelado quanto a licenciatura apresentavam a modalidade seriado. Apenas a partir do ano de 2010 passaram a ser ofertados na modalidade de matrícula por disciplina. A forma de ingresso no curso, desde sua implantação, foi o vestibular, sendo alterada em 2010, quando foi implantado o Sistema de Seleção Unificada - SISU ${ }^{1}$.

\section{OS ESTUDANTES DE GRADUAÇÃO EM FÍSICA DA UFMS: INFLUÊNCIAS CONSTATADAS}

Do total de entrevistados, 51\% ingressaram na universidade no ano de 2010 e 49\% ingressaram antes de 2010 (2007, 2008 e 2009). Em relação à modalidade do curso, $71 \%$ dos alunos participantes são da licenciatura e $29 \%$ cursam o bacharelado. Dentro da estrutura do curso, é permitido que, sob novo vestibular, o estudante mude de habilitação (licenciatura ou bacharelado) quantas vezes quiser, aproveitando as disciplinas comuns. Cerca de 11\% dos entrevistados optaram por fazer essa mudança de modalidade, provavelmente por considerarem que a outra habilitação atenderia melhor as suas necessidades.

Outra informação importante é que a grande maioria dos estudantes entrevistados são oriundos de escolas públicas. O Ensino Fundamental foi cursado em escola pública por $73 \%$ deles, e o Ensino Médio por $60 \%$.

A seguir, apresentamos a análise das questões mais específicas do questionário dividindo-as em três blocos: os professores que esses estudantes trazem na memória, as características do professor rememorado e a opção pelo curso.

\section{a) 0 professor que os estudantes trazem na memória}

As três primeiras questões se referiram ao professor que os estudantes investigados traziam na memória, à disciplina que esse professor ministrava e à opção de curso, caso não tivessem escolhido o curso de Física.

A primeira questão relativa ao interesse deste estudo foi "Quando você se lembra de seus professores, o professor de quem você se lembra de maneira especial era do ensino: () Ensino Fundamental () Ensino Médio () pré-vestibular'. A grande maioria (65\%) dos entrevistados citou os professores do Ensino Médio.

Como questão complementar, perguntamos sobre a disciplina que esse professor ministrava. Muitos estudantes citaram mais de um professor e, em muitos casos, de áreas diferentes. Organizamos a Tabela 1 totalizando as citações, e, por isso, é ultrapassado o número de estudantes investigados. 
Tabela 1: Disciplina ministrada pelo professor lembrado

\begin{tabular}{|l|l|}
\hline Disciplina & $\begin{array}{l}\text { Quantidade de vezes em que o } \\
\text { professor foi mencionado }\end{array}$ \\
\hline Física & 23 \\
\hline Matemática & 18 \\
\hline Química & 10 \\
\hline Português & 6 \\
\hline Biologia & 5 \\
\hline História & 5 \\
\hline Ciências & 4 \\
\hline Ciências Sociais & 2 \\
\hline Filosofia & 1 \\
\hline Artes & 1 \\
\hline
\end{tabular}

Podemos constatar que, de forma predominante, os professores mais lembrados foram os de Física, Matemática e Química, ou seja, do campo das Ciências da Natureza, Matemática e suas Tecnologias, uma das três áreas de conhecimento citadas nos Parâmetros Curriculares Nacionais para o Ensino Médio (BRASIL, 1999). Esse resultado está em sintonia com outros estudos realizados sobre o ensino de Ciências, que apontam a grande influência exercida pelos professores de Ciências em estudantes que buscam carreiras nas Ciências Exatas (PIETROCOLA \& PINHEIRO, 2000). Ainda segundo Pietrocola e Pinheiro (2000), os estudantes estabelecem um vínculo afetivo com as disciplinas quando há um vínculo afetivo com o professor.

Nos cursos de Física da UFMS, tanto a licenciatura quanto o bacharelado, a preferência pela área está presente de forma expressiva, mesmo em uma segunda opção de curso. Os investigados, quando questionados sobre a opção de curso, caso não tivessem escolhido Física, mantiveram-se quase que exclusivamente na área de Ciências Exatas. Para essa questão, os estudantes poderiam escolher uma única opção, sendo que um deles deixou de responder. A Tabela 2 ilustra esse resultado:

Tabela 2: Curso que optariam, caso não tivessem escolhido Física

\begin{tabular}{|l|l|}
\hline Curso escolhido & $\begin{array}{l}\text { Número de alunos que } \\
\text { mencionaram o curso }\end{array}$ \\
\hline Engenharias & 14 \\
\hline Matemática & 7 \\
\hline Química & 4 \\
\hline Ciências da Computação & 3 \\
\hline Outros (exatas) & 5 \\
\hline Outros (humanas e biológicas) & 11 \\
\hline
\end{tabular}


Baseados nos dados das Tabelas 1 e 2 , inferimos que esses alunos possuem um vínculo com os professores da área de Ciências Exatas, visto que muitos se recordam de maneira especial dos professores dessa área e afirmaram, ainda, que se não fossem cursar Física, optariam por um curso da área das Ciências Exatas.

\section{b) As características do professor rememorado}

O segundo foco de análise mais específica refere-se à forma de trabalho do professor que trazem na memória. A pergunta inicial buscava as características desse professor em sala de aula. Nesta análise, utilizamos as mesmas categorias usadas por Quadros et al. (2005), ou seja, as referências ao professor como sendo afetivas, pedagógicas ou de conhecimento.

A Tabela 3 apresenta as categorias de referência e a quantidade de citações para cada uma delas. É importante ressaltar que os números apresentados se referem à quantidade de vezes que cada referência foi citada e não ao número de pesquisados.

Tabela 3: Categorias referentes às características do trabalho do professor citado

\begin{tabular}{|l|l|}
\hline Referência da memória & Número de citações \\
\hline Pedagógica & 23 \\
\hline Afetiva & 19 \\
\hline Conhecimento & 16 \\
\hline
\end{tabular}

$\mathrm{Na}$ categoria referência pedagógica, foram incluídas as características relacionadas ao ensino e à aprendizagem, que fazem menção à metodologia e/ou à forma de explicar o conteúdo, ao planejamento de ações, ao aproveitamento do tempo, aos materiais usados, à discussão de temas atuais, entre outras. As citações que seguem podem exemplificar essa classificação.

"Ele era educador e não só professor, discutia com a turma diversos aspectos relacionados à realidade da sociedade, [...], e sua aula era extremamente motivadora." (Estudante 1)

"Didática, preocupação com o aprendizado dos alunos." (Estudante 2)

"Levavam novidades para a sala de aula." (Estudante 3)

Os aspectos didáticos foram constantemente lembrados por nossos investigados, assim como no estudo de Quadros et al. (2005). Para a maioria dos entrevistados, tanto da UFMG quanto da UFMS, a característica mais importante no professor está relacionada a como ensinar. Ao afirmar que o professor "levava novidades para a sala de aula" (Estudante 1), o estudante deixa claro que o professor fazia mais do que simplesmente transmitir conteúdo. Relacionar o conteúdo de sala de aula com o contexto social e apresentar aplicações tecnológicas do conhecimento trabalhado em sala de aula, eram, provavelmente, características consideradas importantes em um professor, segundo os estudantes investigados neste trabalho. 
Ainda nessa categoria incluímos um pequeno grupo de estudantes que classificou como importante em seus professores os aspectos disciplinadores. Apesar de não nos atermos a esse item, citamos alguns comentários referentes a ele.

\section{“[...]tinha um total dominio da classe [...]."(Estudante 4)}

"[...], era disciplinador [...]." (Estudante 5)

$\mathrm{Na}$ categoria referência afetiva foram enquadradas aquelas que valorizavam a relação professor-aluno. Incluímos nessa categoria itens que se referem à amizade, ao companheirismo, ao respeito, entre outros itens. Os professores cujas características foram incluídas nesse grupo foram descritos como atenciosos, compreensivos, amigos, engraçados/bem humorados. As citações abaixo podem exemplificar essa classificação.

\section{"Bom humor, amigo." (Estudante 6) \\ "Eram educados, respeitavam, ouviam, levavam a sério os alunos." (Estudante 7)}

Essas frases dos estudantes de Física da UFMS apresentam aspectos relacionados à afetividade, a qual assume um papel importante na relação professor/aluno, também presente em outros estudos. Quadros et al. (2005) apontam essas características afetivas nos alunos da UFMG e dão destaque para as características como amizade, companheirismo e respeito, valores lembrados pelos alunos pesquisados naquele trabalho. Pietrocola e Pinheiro (2000) também comentam sobre a importância da afetividade na relação entre professor e estudantes. Eles defendem que mesmo que o estudante não crie vínculos afetivos com o conhecimento em si, a postura do professor pode fazer isso, tornando as aulas mais proveitosas. Nessa mesma linha, o estudo de Custódio (2007) trata dos vínculos afetivos entre o estudante e o conteúdo, e também entre os estudantes e professores. $\mathrm{O}$ autor constatou que os estudantes apresentavam vínculos com os conteúdos de Física, e um dos agentes responsáveis por esse vínculo era o professor.

Assim como nos dados acima citados, os resultados obtidos em nosso trabalho confirmam a importância de um ambiente afetivo em sala de aula para que os estudantes desenvolvam interesse pelo componente curricular trabalhado. Podemos inferir que esse ambiente afetivo é importante para a aprendizagem.

No terceiro grupo aparecem as características relacionadas ao conhecimento. Nele, os entrevistados tratam do saber do professor e de sua capacidade de dissertar sobre o conteúdo da aula, como é possível constatar nas falas de alguns estudantes:

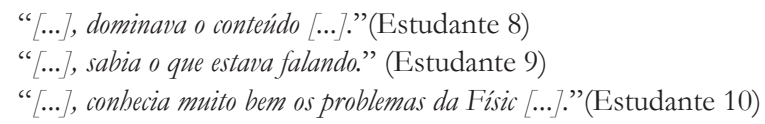

No trabalho de Quadros et al. (2005), o conhecimento foi uma característica pouco citada pelos estudantes, apesar do domínio do conteúdo ser algo que 
chamava a atenção durante as aulas de seus professores. Entre os estudantes de Física da UFMS, essa característica se mostrou importante, apesar de ser citada menos vezes quando comparada à didática e à afetividade.

De maneira geral, constatamos que os resultados obtidos neste trabalho são semelhantes aos obtidos por Quadros et al. (2005) em sua pesquisa com os estudantes do curso de Química. Em ambos, as características pedagógicas e afetivas dos professores são as mais lembradas pelos estudantes. Ao que parece, o "como ensinar" é mais importante do que o domínio de conteúdo em si quando os estudantes de graduação rememoram as características de um professor que tiveram e que gostaram. Porém, apesar dessas semelhanças, percebemos que os alunos da UFMS valorizam mais o conhecimento de conteúdo (28\% das características são relativas ao conhecimento do professor) do que os estudantes pesquisados por Quadros et al. (2005). É provável que essa diferença se dê em função da diferença entre a realidade vivida pelos estudantes da UFMG e os da UFMS.

\section{c) A escolha do curso de Física}

As questões seguintes referem-se à escolha do curso de Física pelos estudantes investigados e os motivos que os levaram a essa escolha. Tendo como base os estudos de Martini (2006) e Custódio (2007), classificamos os motivos apresentados aos estudantes em: afinidade com as Ciências Exatas, mercado de trabalho, vontade de desvendar e explicar a natureza, influência de materiais de divulgação, influência do professor de Física, e um último grupo em que foram elencadas as respostas que não apresentaram justificativas para a escolha.

Com essas categorias os estudantes deveriam indicar o grau de importância, numa escala numérica de 1 (mais importante) a 5 (menos importante). Alguns estudantes apresentaram respostas contraditórias para essas duas questões e, por isso, foram desconsideradas da análise. Nesses casos, o estudante inverteu a valorização, trocando o caráter "mais importante" atribuído pelo valor 1 , por pouco importante, que deveria ser atribuído ao número 5. Usamos, portanto, na presente análise, 37 questionários. Os resultados obtidos estão na Tabela 4 a seguir:

Tabela 4: Valorização dos itens, como influências na escolha do curso

\begin{tabular}{|l|l|l|l|l|l|}
\hline & $\begin{array}{l}\text { (1) } \\
\text { Mais } \\
\text { importante }\end{array}$ & (2) & (3) & (4) & $\begin{array}{l}\text { (5) } \\
\text { Menos } \\
\text { importante }\end{array}$ \\
\hline Interesse / afinidade pela Física & 24 & 6 & 2 & 5 & 0 \\
\hline Mercado de trabalho & 17 & 7 & 7 & 1 & 5 \\
\hline Localização da universidade & 7 & 3 & 8 & 4 & 15 \\
\hline Influência do professor & 5 & 8 & 9 & 6 & 9 \\
\hline Influência da família & 4 & 3 & 5 & 4 & 21 \\
\hline Influência dos amigos & 2 & 2 & 5 & 4 & 24 \\
\hline
\end{tabular}


Os dados indicam que o aspecto que mais influenciou os estudantes na escolha do curso foi a afinidade com a Física, seguido pelo mercado de trabalho, que ainda é amplo para os professores dessa disciplina. Sabe-se que há uma grande demanda por professores de Física e um campo mais restrito ao bacharel em Física. Talvez o mercado de trabalho tenha sido uma opção dos estudantes de licenciatura. A indicação do interesse pela área por causa do mercado de trabalho mostrou-se semelhante aos resultados encontrados por Martini (2006) ao pesquisar estudantes da rede pública de ensino de Campinas na escolha pelo curso de Ensino Médio técnico em Química.

A localização da universidade e a influência de família e amigos foram consideradas como pouco representativas. Já a influência do professor não está entre os fatores mais importantes, mas também não foi desconsiderada, já que aparece como segunda e terceira opções. Este é outro aspecto que também foi constatado no estudo de Martini (2006), quando os estudantes por ela pesquisados também atribuíram média influência do professor na futura escolha do curso.

Em síntese, destacamos que o estudante de graduação em Física da UFMS não coloca o o professor recordado como o principal agente na sua escolha para a carreira de físico e professor de Física. Para ele, a afinidade com o campo das Ciências Exatas e as perspectivas de mercado de trabalho foram os fatores mais marcantes para essa escolha.

\section{CONSIDERACְÕES FINAIS}

O objetivo deste trabalho foi compreender a influência que o professor de Ciências pode exercer em seus alunos quando da escolha de um curso de graduação. Além disso, buscamos identificar os principais aspectos que permeiam a relação entre professor e estudante, que são considerados importantes pelos graduandos em Física, e os demais fatores que contribuem para que os estudantes de Ensino Médio optem pela carreira de físico.

Dentre os resultados, a influência do professor de Ciências na escolha do curso não foi citada como importante para a maior parte dos estudantes da graduação em Física da UFMS. Porém, ao rememorar um professor que os tenha marcado de alguma forma, os mais citados foram os professores de Física ou da área de Ciências da Natureza.

Para esses estudantes, a afinidade com a área de Física é lembrada como a maior influência na opção pelo curso. Mas, é possível que essa afinidade com o conteúdo seja fruto do trabalho dos professores que ministraram as disciplinas relativas a esse conteúdo. De acordo com o trabalho de Pietrocola e Pinheiro (2000), foi observado que os vínculos afetivos com as disciplinas estão ligados ao vínculo afetivo com os professores que as ministram.

É importante salientar que as decisões que o professor toma em sala de aula têm inúmeras implicações nas opções que os estudantes fazem. Essas 
decisões - prática pedagógica, ouvir o aluno, entre outras atitudes do professor - acabam por influenciar na relação que esses estudantes desenvolvem com os objetos de conhecimento escolar, ou seja, com o conteúdo da disciplina ministrada. Portanto, inferimos que os professores de Ciências influenciaram, mesmo que indiretamente, na opção dos estudantes de Física da UFMS pela carreira na área de Ciências Exatas.

Sobre os aspectos que permeiam a relação entre professor e estudantes, na sala de aula, também identificamos a presença da afetividade. As relações construídas em sala de aula são importantes para esses estudantes. Tal qual o trabalho de Quadros et al. (2005), o estudante do curso de Física da UFMS vê os aspectos didáticos de uma aula e as relações afetivas que ele estabelece com seu professor como fatores importantes em sua vida escolar. O ambiente afetivo em sala de aula acaba por propiciar um modelo de professor com o qual os estudantes conseguem se identificar, e nos parece provável que se identifiquem também com o conteúdo ministrado por esse professor.

Villani e Cabral (1997), conforme já citado, afirmam que o engajamento do estudante nas aulas é favorecido quando o professor ouve seus alunos, valoriza suas ideias e incentiva a discussão dessas ideias. Essas atitudes criam um ambiente afetivo na relação em sala de aula. Ao descreverem um professor que admiram e vincularem essa admiração a aspectos afetivos, os estudantes tornam explícita a importância dos aspectos afetivos.

Em relação à opção pelo curso de Física, tanto entre licenciandos quanto entre bacharelandos, os estudantes dão mais valor a suas perspectivas de trabalho e à afinidade pelas Ciências Exatas como fatores fundamentais em suas escolhas.

Conforme já foi exposto, o estudo de Martini (2006) obteve resultados semelhantes com estudantes do curso de Ensino Técnico em Química na região de Campinas, ou seja, o mercado de trabalho e a afinidade com a Química foram fatores marcantes na escolha do curso. Custódio (2007) também obteve resultados semelhantes quanto à questão da escolha da Física como opção de curso dos estudantes da UFSC, que também demonstraram afinidade com a área.

Acreditamos que os sujeitos pesquisados neste trabalho estabeleceram um vínculo afetivo com o conhecimento físico que, provavelmente, teve origem na sala de aula. O professor é aquele que tem o papel de potencializar uma motivação já existente pelas ciências em seus alunos, ou de estimular o aparecimento dela, caso não exista. Mas como isso pode ser feito? O fato de esses estudantes citarem a didática do professor e as características que categorizamos como afetivas como fatores importantes no professor que admiram sinaliza que os professores que esses estudantes tiveram (e que admiram até hoje) também foram responsáveis pela afinidade desenvolvida com a área/conteúdo.

O professor, como agente importante na escolha pela área que o estudante vai seguir, não pode se isentar de sua parcela de responsabilidade. Ele necessita participar de programas de formação continuada, buscando práticas pedagógicas atuais. É preciso destacar que o professor tem um papel importante na formação 
dos estudantes e que fazer da sala de aula um ambiente afetivo, valorizando o estudante e as ideias que este leva para a sala, é fundamental. Ensinar conhecimentos específicos de Física é importante, mas desenvolver o interesse do estudante pela Ciência, promover seu engajamento nas aulas e produzir aprendizagem ainda são os grandes desafios para os professores.

\section{NOTA}

${ }^{1}$ É o sistema informatizado, gerenciado pelo Ministério da Educação, por meio do qual as instituições públicas de Educação Superior participantes selecionam novos estudantes exclusivamente pela nota obtida no Exame Nacional de Ensino Médio (Enem).

\section{REFERÊNCIAS BIBLIOGRÁFICAS}

ANDRÉ, M. E. D. A. Etnografia da Prática Escolar. São Paulo : Ed. Papirus. $16 . \quad$ ed. 2009.

BRASIL. Ministério da Educação. Secretaria de Educação Média e Tecnológica. Parâmetros Curriculares Nacionais para o Ensino Médio. Brasília: Ministério da Educação, 1999.

CUSTÓDIO, J. F. Explicando explicações na educação científica: domínio cognitivo, status afetivo e sentimento de entendimento. 2007. 249 fl. Tese (Doutorado em Educação Científica e Tecnológica) - Universidade Federal de Santa Catarina, Florianópolis, 2007.

DALRI, J.; MATTOS, C. R. Aspectos afetivos-cognitivos na aprendizagem e suas influências na escolha da profissão de professor de Física: um exemplo In: ENCONTRO DE PESQUISA EM ENSINO DE FÍSICA, 11., 2008. Curitiba. Anais... Curitiba: SBF, 2008.

GARNICA, A. V. M. Algumas notas sobre Pesquisa Qualitativa e Fenomenologia. Interface. Comunicação, Saúde, Educaşão, Botucatu, SP, v.1, n.1, p. 109-122, 1997.

GIL, A. C., Métodos e técnicas de pesquisa social. São Paulo: Atlas, 2006.

MACHIORE, L. W. O. A.; ALENCAR, E. M. L. S. Motivação para aprender em alunos do ensino médio. Educação Temática Digital, Campinas, v.10, p. 105-123, 2009.

MARTINI, A. M. A infuência da relação entre o professor de química e os alunos na escolha pela Química como área de atuação profissional. 2006. Trabalho (Conclusão de Curso) - Faculdade de Educação da Universidade de Campinas, Campinas, 2006.

MORTIMER, E. F. Construtivismo, Mudança conceitual e Ensino de Ciências: para onde vamos? Investigacõos em Ensino de Ciências, Porto Alegre, v.1, n. 1, p.20-39, 1996.

MORTIMER, E. F. e SCOT'T, P. Meaning making in secondary science classrooms. Buckingham: Open University Press, 2003.

PIETROCOLA, M., PINHEIRO, T. F. Modelos e afetividade. ENCONTRO DE PESQUISA EM ENSINO DE FÍSICA, 7., 2000. Florianópolis. Anais... Florianópolis: Sociedade Brasileira de Física, 2000.

QUADROS, A. L. de, et al. Os professores que tivemos e a formação da nossa identidade como docentes: um encontro com nossa memória. Revista Ensaio Pesquisa em Educação em Ciências, Belo Horizonte, v. 7 n. 01, 2005.

SCHNETZLER, R. P. Construção do Conhecimento e Ensino de Ciências. Em Aberto, Brasília, v. 11, n. 55, p.16-23, 1992.

SILVA, J. B.; SCHNEIDER, E. J. Aspectos sócio-afetivos do processo de ensino e aprendizagem. Revista de divulgaşão técnico-científica do ICPG, Blumenau, SC, v. 3, n. 11. p. 83-87. Jul/Dez 2007.

VILLANI, A.; CABRAL, T. C. B. Mudança conceitual, subjetividade e psicanálise. Investigações em Ensino de Ciências, Porto Alegre, v. 2, n. 1, p. 43-61, 1997. 
Bruno dos Santos Simões | Ana Luiza de Quadros | Simoni Tormöhlen Gehlen Hamilton Perez Soares | Rodolfo Langhi

VON HOHENDORFF, C. M., Cultura é aquilo que fica de tudo que se esquece. Psicanálise e educação: uma transmissão possível. Revista da Associação Psicanalítica de Porto Alegre, Porto Alegre, v. IX, n. 16, p. 52-60, 1999.

Data do Recebimento: 10/4/2011

Data de Aprovação: 21/10/2011

Data da Versão Final: 25/10/2011 